\title{
Preparation of a New Borehole Sealing Material of Coal Seam Water Infusion
}

\author{
Gang Wang $\mathbb{D},{ }^{1,2}$ Hao Liu $\mathbb{D}^{2},{ }^{2}$ Jianhong Luo, ${ }^{3}$ Hao Xu $\mathbb{D},{ }^{2}$ Qiqi Liu $\left(\mathbb{D},{ }^{2}\right.$ Xiaohua Zhou $\left(\mathbb{D},{ }^{2}\right.$ \\ Yanwei Hu $\left(\mathbb{D},^{2}\right.$ and Xuelin Liu $\mathbb{D D}^{2}$ \\ ${ }^{1}$ Mine Disaster Prevention and Control-Ministry of State Key Laboratory Breeding Base, Shandong University of Science and \\ Technology, Qingdao 266590, China \\ ${ }^{2}$ College of Mining and Safety Engineering, Shandong University of Science and Technology, Qingdao 266590, China \\ ${ }^{3}$ Department of Chemical Engineering, Sichuan University, Chengdu, Sichuan 610065, China
}

Correspondence should be addressed to Gang Wang; gang.wang@sdust.edu.cn

Received 12 December 2017; Accepted 27 February 2018; Published 20 March 2018

Academic Editor: Federica Bondioli

Copyright () 2018 Gang Wang et al. This is an open access article distributed under the Creative Commons Attribution License, which permits unrestricted use, distribution, and reproduction in any medium, provided the original work is properly cited.

To improve the borehole sealing effect of coal seam water infusion, especially that of coal seam with low permeability and high rigidity, this study investigated the performance test optimization of two cement-based sealing materials. The borehole sealing effect of this coal seam requires high-pressure water infusion. Result shows that when the water-cement ratio is 0.4 and the amount of fiber expansive agent is $10 \%$, the new borehole sealing material displays microexpansion. In addition, the 1-day compressive strength reaches $16 \mathrm{MPa}$. This result satisfies the material compressive strength requirement under $30 \mathrm{MPa}$ high-pressure water infusion. The sealing performance is also excellent. According to the scanning electron microscopy analysis of new borehole and traditional borehole sealing materials, the surface of new borehole sealing material shows no holes and possesses compactness. The sealing effect is superior to that of other traditional sealing materials. This effect can satisfy the sealing requirement of coal seam water infusion. The new borehole sealing material is considerably significant for the improvement of the water infusion effect.

\section{Introduction}

As one of the major resources in China, coal accounts for over $70 \%$ of primary energy [1]. A considerable amount of dust, generated during coal mining production threatens the physical health of mining workers and safe production of mines to a substantial degree $[2,3]$. Water infusion acts as the most efficient method of dust prevention in coal face. The key process of coal seam water infusion is borehole sealing, whose quality influences the effect of coal seam water infusion directly $[4,5]$. Nevertheless, in the process of coal mine drilling, the fissure network inside boreholes further develops. The stress field of roadway surrounding rocks underground coal mines also exerts remarkable influence on fissure development. Thus, borehole sealing is a significant challenge.

Optimization of borehole sealing material determines the success of borehole sealing [6]. Currently in the process of underground coal mine production, all kinds of borehole sealing materials are used; these materials mainly include clay material, high-water material, polymer material, and cement-based sealing material. Clay material is easy to operate and convenient for borehole sealing at low cost. However, the rigidity of clay material should be moderate because high softness or high hardness can both lead to poor sealing effect. As a new type of special cement composite material, high-water material displays high condensation rate, quick development of compressive strength, and microexpansion. Nonetheless, given the abundant composition, high-water material is costly. As a typical example of polymer material, polyurethane shows the advantages of high expansibility, high borehole sealing rate, and convenience, but it displays weak cementing power and low compressive strength. Polyurethane can also be toxic and expensive. With a long history of application and investigation, cement-based borehole sealing material also 
TABLE 1: Fiber expansive agent performance parameter.

\begin{tabular}{lccccc}
\hline Type & Form & Color & Water content & pH & Chloride content \\
\hline EA & Powder & Dark brown & $3.0 \%$ & $7.0-8.0$ & $0.01 \%$ \\
\hline
\end{tabular}

exhibits many advantages, such as a wide range of raw material sources, low cost, and simple operation. Moreover, cement-based borehole material demonstrates special advantages in the practice of borehole sealing; for example, its excellent mechanical property can support the borehole wall and resist the disturbances caused by geological factors in mining activities. Under the condition of borehole pressurized sealing, cement slurry can permeate the fissures of borehole wall and seal leaky fissures effectively. Therefore, cement-based borehole sealing material is widely used in the practice of coal mining borehole sealing $[7,8]$.

In spite of these advantages, cement-based borehole sealing material suffers from shrinkage-cracking. The compressive strength of this material also develops slowly, and the setting time is long. In view of these drawbacks of cement-based borehole sealing material, local and international scholars carried out many studies. Some scholars found that addition of a certain amount of fly ash into cement-based borehole sealing material reduces the material hydration heat, restrains shrinkage-cracking, and improves the material synthetic performance. According to Termkhajornkit et al. [9] and Atiş [10], addition of a certain amount of fly ash into concrete helps restrain shrinkage considerably and improve the compressive strength. Nath and Sarker [11] and Chindaprasirt et al. [12] studied the durability of fly ash and cement slurry comprehensively in terms of compressive strength, shrinkage, Chloride ion adsorption, and permeability. They also identified that appropriate addition of fly ash contributes to the improvement of cement slurry durability. Nevertheless, the influence of fly ash on cement slurry is complex. Fly ash overdose results in negative effects. Hence, synthetic performance, inconvenient operation, and low strength during the early stage should be taken into account. Lim et al. [13] believed that sand gradation also exerts a significant effect on the properties of cement slurry; the strength and durability of solidified finesand-cement slurry are better than those of coarse sand under high water-cement ratio. Cement mortar is cheap and easy to operate, but it easily suffers from shrinkage and cracking. Ni et al. [14] explored the microcharacteristics of borehole sealing composite material that is composed of polyurethane and expansive cement. Ge et al. [15] proposed a kind of borehole sealing material, which is a mixture of cement, early-strength water-reducing admixture, polypropylene fiber, and water. The material shows low shrinkage rate and high compressive strength, but the required borehole sealing compressive strength can be satisfied for at least 3 days after sealing. The construction period is also extended. Zhai et al. [16] analyzed the sealing performance of flexible gel sealing material. This material exhibits excellent compactness, stability, fluidity, and permeability. However, given the multiple composition and complicated configuration, the material cost is high.
Although local and international scholars conducted a large number of research on cement-based borehole sealing material, the required performance and cost cannot be satisfied simultaneously [17-19]. The present study uses 32.5R Portland cement and 52.5R sulfoaluminate cement as major ingredients. Fiber expansive agent and early-strength water-reducing admixture are also added into the cement. Material optimization against problems of cement borehole sealing, such as low strength in the early stage, high shrinkage rate, and poor impact resistance, is also investigated. According to the experimental field result of $\mathrm{Ge}$ et al. [20] which plugging of $30 \mathrm{MPa}$ water infusion pressure requires a borehole sealing material compressive strength of 14.4 MPa, the preset value of the compressive strength should be at least 14.4 $\mathrm{MPa}$. Additionally, the required expansion property is microexpansion. To satisfy these two performance requirements, borehole sealing performance is also explored through tests under different water-cement ratios and additives amounts. The optimum material proportion is determined so that a new type of borehole sealing material can be developed.

\section{Test}

2.1. Raw Materials. On the basis of the performance requirements of borehole sealing, two different kinds of cement are selected as major ingredients of two sealing materials (materials 1, and 2). The major ingredients of materials 1 and 2 are ordinary 32.5R Portland cement and 52.5R sulfoaluminate cement, respectively. These cements were both purchased from China Gezhouba Group Cement Co. Ltd. (Hubei, China). Fiber expansive agent and earlystrength water-reducing admixture are the minor ingredients of material 1. Only the fiber expansive agent is selected as the minor ingredient of material 2. The fiber expansive agent (Shanxi Qinfen Building Material Co., Ltd.) is a compound of calcium silicate and polypropylene fiber; the design amount of this admixture is $8.0 \%-12.0 \%$ of gel material amount. The performance parameter of this expansive agent is shown in Table 1. The early-strength waterreducing admixture (Qingdao Hongsha Admixture) is composed of calcium lignosulfonate and fly ash, and its design amount is $2 \%-8 \%$ of gel material amount.

2.2. Test Plan. To obtain the borehole sealing material proportion that satisfies the abovementioned requirements, the borehole sealing material performances, such as expansion performance and compressive strength, are evaluated under different water-cement and admixture ratios. The water-cement ratios of material 1 are $0.4,0.5$, and 0.6 in sequence. The fiber expansive agent and early-strength water-reducing admixture are added through combinations of composite ratio. The water-cement ratio of material 
TABLE 2: Material proportion.

\begin{tabular}{|c|c|c|c|c|c|c|c|}
\hline Admixture & & & & oporti & & & \\
\hline Amount of fiber expansive agent & $8 \%$ & $9 \%$ & $10 \%$ & $11 \%$ & $12 \%$ & & \\
\hline Amount of early-strength water-reducing admixture & $2 \%$ & $3 \%$ & $4 \%$ & $5 \%$ & $6 \%$ & $7 \%$ & $8 \%$ \\
\hline
\end{tabular}

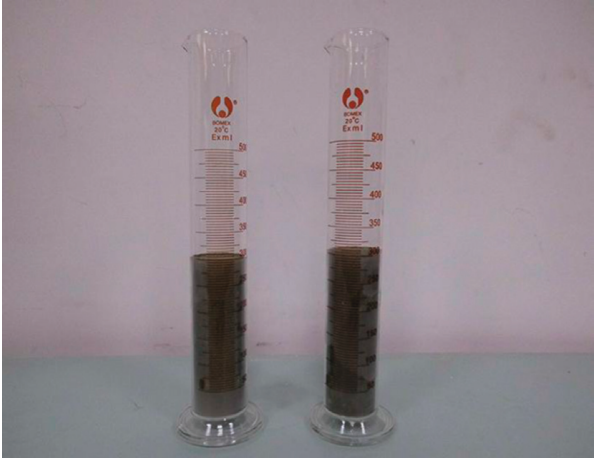

FIGURE 1: Evaluation of expansion performance.

2 is $0.4,0.45$, and 0.5 in sequence. The design amounts of the two kinds of fiber expansive agents are consistent with each other. The amounts of fiber expansive agent and earlystrength water-reducing admixture are shown in Table 2.

2.2.1. Expansion Performance Test. In the expansion performance test, well-prepared slurry $(300 \mathrm{ml})$ is poured into a $500 \mathrm{ml}$ beaker. Five test specimens are prepared for each composition ratio and shown in Figure 1. In the laboratory curing condition of $25^{\circ}-30^{\circ} \mathrm{C}$ lab, the volume is read every 2 min and recorded as V1, V2, V3, V4, and Vn sequentially, where $\mathrm{V} n$ is the final volume. The recorded $\mathrm{V} n$ is the average of five specimens.

2.2.2. Uniaxial Compressive Strength Test. The wall of the mold $(70.7 \mathrm{~mm} \times 70.7 \mathrm{~mm} \times 70.7 \mathrm{~mm})$ is coated with a layer of release agent and poured slurry, which is well stirred into the mold. A vibrating table is used to densify the slurry, which is poured into the curing box of $95 \%$ relative humidity and $20^{\circ} \mathrm{C}$ temperature until the scheduled age. Subsequently, the sample is demolded. The pressure testing machine of electrohydraulic servo is used to assess the uniaxial compressive strength of the sample after 1-day curing with a loading speed of $0.3 \mathrm{MPa} / \mathrm{s}$. The test is terminated when the sample is broken. The test equipment is shown in Figure 2.

2.2.3. Microstructure Comparisons. JSM-6510LV high- and low-vacuum scanning electron microscope is used to observe the structure and fissure of borehole sealing material in the reaction process. The microscope amplification ranges from quintupling to 300,000 times. The actual product is shown in Figure 3.

The scanning electron microscope is used to observe and analyze the microstructure of polyurethane, cement mortar, and new borehole sealing material. The test procedures are as follows:

(1) Prepare two groups of polyurethane, cement mortar, and new borehole sealing material in beakers and record them as groups A and B. Place them in the curing box at $30^{\circ} \mathrm{C}$ and $101.325 \mathrm{kPa}$ with group $\mathrm{A}$ for 1 day and group $B$ for 7 days.

(2) To observe the microstructure of specimens, polish well-cured sample into a cylinder sample $(10 \mathrm{~mm}$, radius, and $1 \mathrm{~mm}$, thickness).

(3) Soak the sample in alcohol for 5 min to remove dust from the sample surface. Further, purge the sample with an ear washing bulb to ensure that the surface is free from dust. Afterward, spray gold on the sample.

(4) Observe the material microstructure with scanning electron microscope.

\section{Test Result and Discussion}

3.1. Expansion Performance Test. For material 1, the slurry with a water-cement ratio of 0.4 shows high viscosity and low fluidity, thereby causing difficulty in pumping. When the water-cement ratio increases to 0.6 , slurry bleeding occurs. Consequently, a large amount of free water is exuded on the slurry surface. The setting and hardening of material are affected, and the water retention capacity of material decreases. A large quantity of free water evaporates after setting, which reduces the material volume. As a consequence, the water-cement ratio of material 1 is 0.5 . The variation of expansion performance with admixture is shown in Figure 4. The expansion performance and compressive strength of material 2 are evaluated, when the watercement ratio of the slurry is $0.4,0.45$, and 0.5 , and the mixing amount of fiber expansive agent is $8 \%, 9 \%, 10 \%, 11 \%$, and $12 \%$. The variation of expansion performance with watercement ratio and amount admixture is shown in Figure 4.

According to Figure 4 (the icon being early-strength water-reducing agent), under fixed water-cement ratio and invariable amount of early-strength water-reducing agent, the final volume of material 1 increases with the amount of fiber expansive agent. When the early-strength waterreducing agent is $7 \%$, the final expansive volume of material 1 increases the fastest. Thus, an improved condition is created for the expansion of material to fissures around after grouting. Material composition ratios above the dotted line expand the material slightly. To further optimize the composition ratio of material 1 , the compressive strength test results should be analyzed to draw the final conclusion.

Figure 5 shows that the final volume of material 2 decreases with the increased water-cement ratio. Under the 


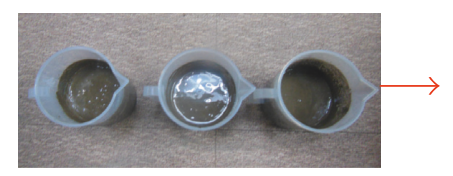

Slurry

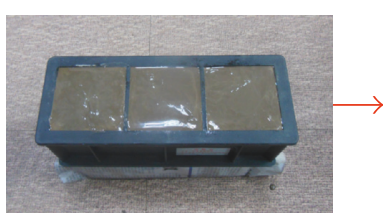

Pour into the mold

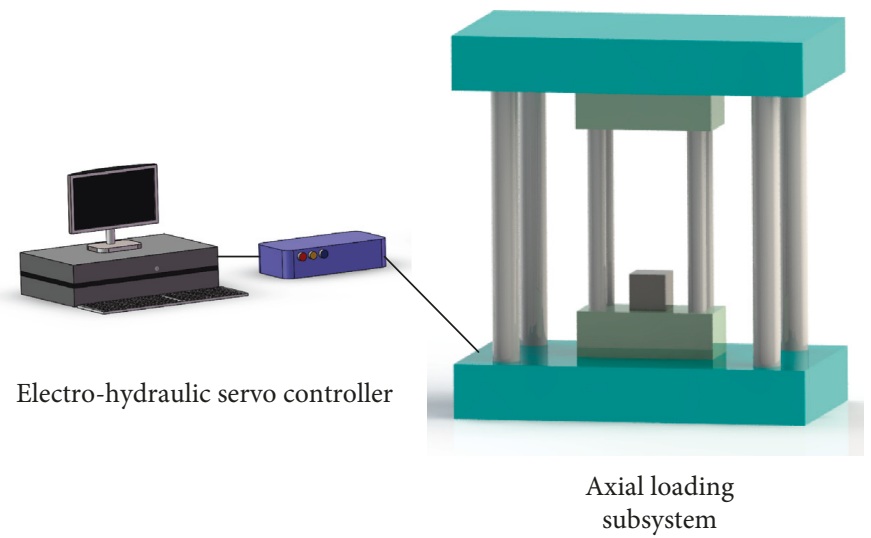

subsystem

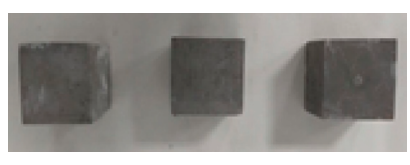

Sample

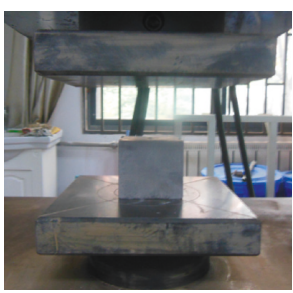

Axial loading subsystem

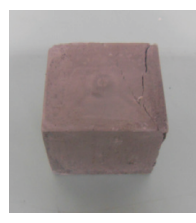

Broken samples

FIgURE 2: Compressive strength evaluation.

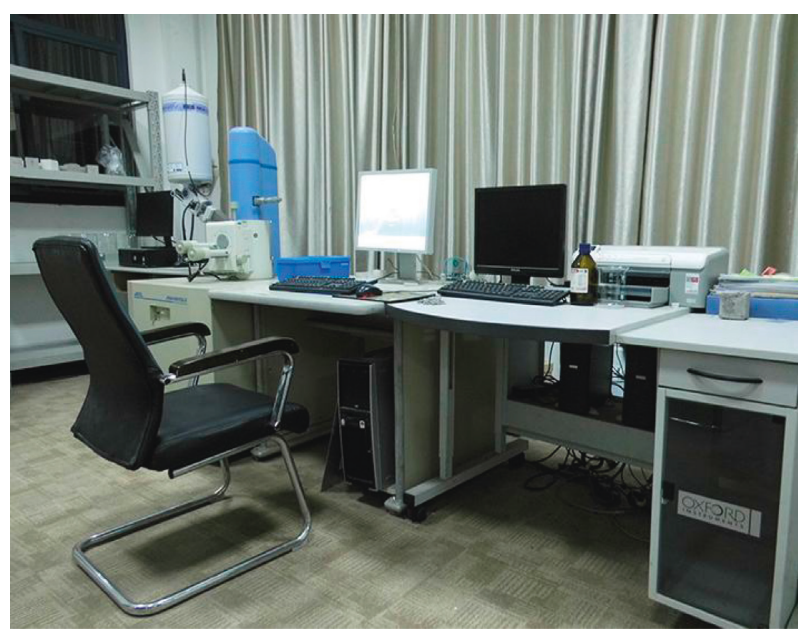

FIgURE 3: Scanning electron microscope.

same water-cement ratio, the final volume of material 2 increases with the amount of fiber expansive agent. Watercement ratio is the main factor affecting the expansion performance of material 2. When the water-cement ratio is 0.5 , the favorable fluidity of material 2 is conducive to grouting, but the microexpansion requirements are unsatisfied. When the water-cement ratio is 0.4 or 0.45 , the adjustment of the amount of fiber expansive agent helps expand material 2. Consequently, the compressive strength of material 2 is evaluated under the water-cement ratio of 0.4

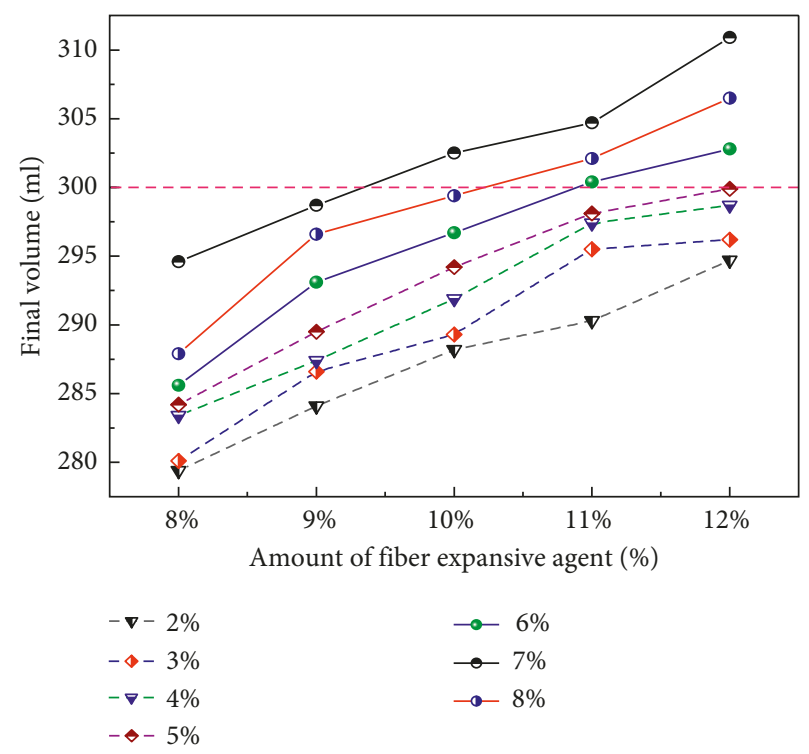

FIgURE 4: Material volume varies with composition ratio.

and 0.45 so as to further optimize composition ratio of material 2.

3.2. Compressive Strength Test. Figure 6 illustrates that after 1 -day setting of material 1, the compressive strength remains under $3.5 \mathrm{MPa}$ regardless of the variation in the composition ratio of admixture. This value fails to satisfy 


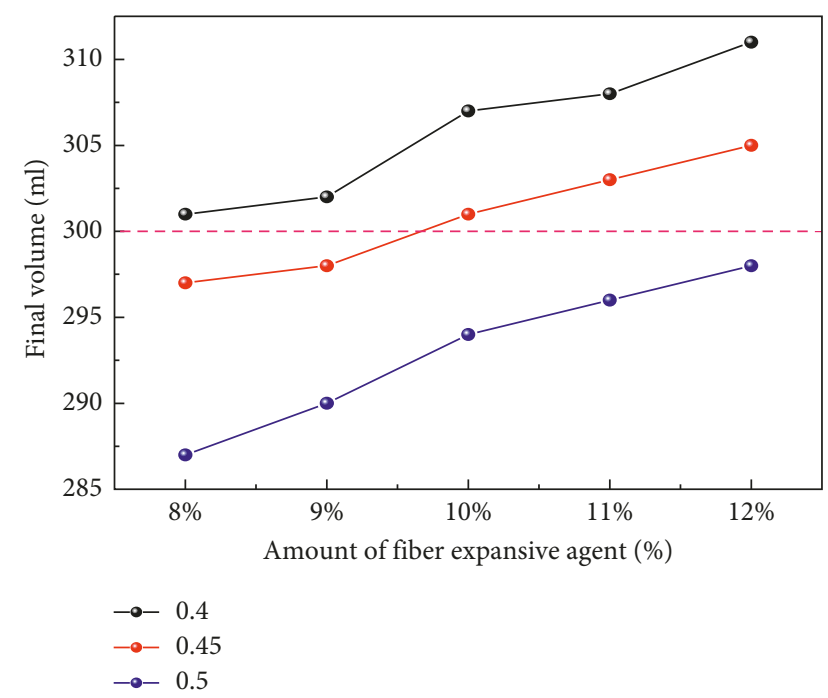

Figure 5: Expansion performance of material varies with the amount of fiber expansive agent.

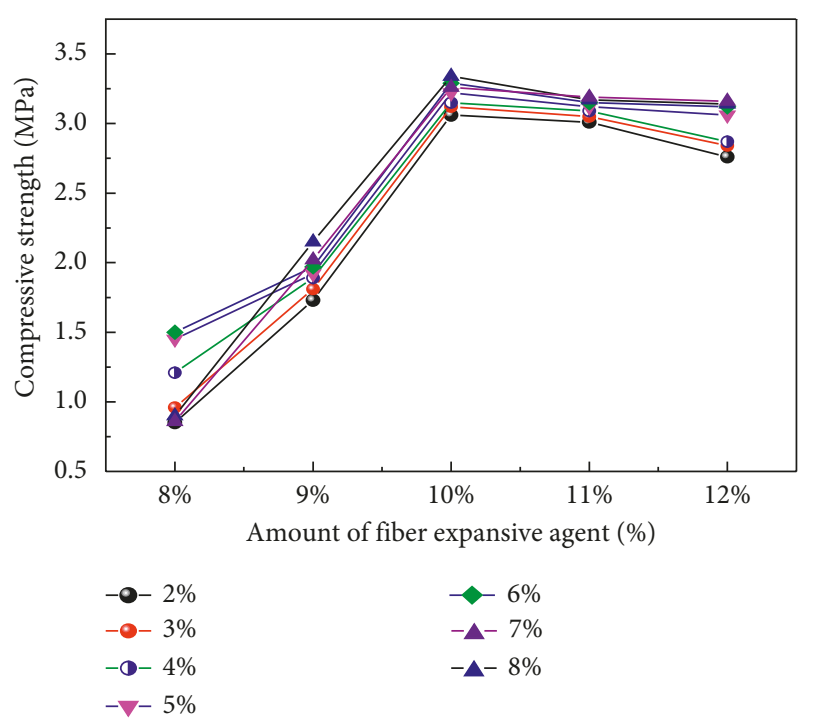

Figure 6: Compressive strength of material varies with composition ratio.

the preset value requirements of borehole sealing material. Given the long setting time of $32.5 \mathrm{R}$ cement, the compressive strength after 1 day setting is considerably less than the final strength. At least 3 days of setting time is needed after borehole sealing to satisfy the strength requirement of water infusion so that the construction period will be delayed.

Figure 7 presents that the compressive strength at 0.4 water-cement ratio is constantly higher than that at 0.5 , when the amount of fiber expansive agent of material 2 is less than $12 \%$. Furthermore, many fissures are present on material surface when the water-cement ratio is 0.45 . Decreased compactness is harmful to borehole sealing. Therefore, the selected water-cement ratio of the new material is 0.4 . When

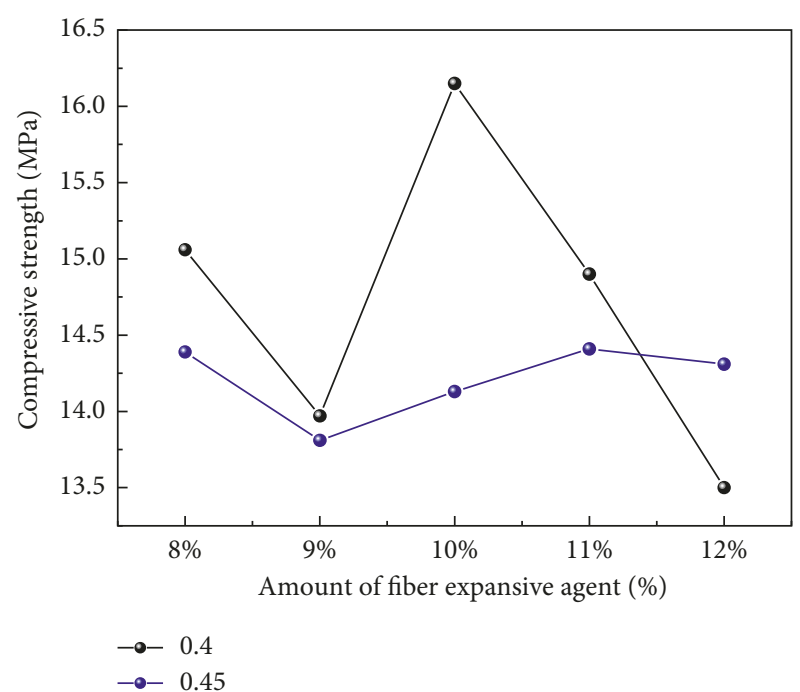

FIgURE 7: Compressive strength varies with fiber expansive agent.

the amount of fiber expansive agent is $10 \%$, the compressive strength is the highest at $16 \mathrm{MPa}$, which is higher than the preset value of $14.4 \mathrm{MPa}$. The preset value requirements of the compressive strength of borehole sealing are fully satisfied.

According to the expansion performance and compressive strength tests of materials 1 and 2, material 2 is the new borehole sealing material. When the water-cement ratio is 0.4 and the amount of fiber expansive agent is $10 \%$, material 2 expands slightly and 1-day compressive strength reaches $16 \mathrm{MPa}$. The material compressive strength requirements under $30 \mathrm{MPa}$ water infusion pressure and the site construction needs are both satisfied. Thus, the composition ratio is the optimum composition.

3.3. Microstructure Comparisons. The microstructure comparisons of the new material, polyurethane, and cement mortar are as shown in Figure 8.

Figure 8(a) shows that the interior structure of polyurethane presents honeycomb-like reticular formation when magnified 50 times with large interior pore space. Cavity array is formed, and the diameter of each cavity is $0.1-0.5 \mathrm{~mm}$. Interconnecting holes between adjacent cavities also occur, which result in poor overall compactness. Figure 8(c) presents the amplified picture (500x) after 1 day setting of cement mortar. Many pores can be observed on its surface, and the compactness is poor. Figure $8(\mathrm{e})$ is illustrates the amplified picture (500x) of the new material. The surface of the new material is compact without any holes and fissures. Consequently, leakage can be restrained effectively when water passes through the material in the process of coal seam water infusion. In addition, the influence of borehole sealing material on water infusion effect can be prevented. As shown in Figure 8(b), macroholes are formed on the surface of polyurethane 7 days later. Hence, the PU compactness is poor. Figure $8(\mathrm{~d})$ shows that the cement mortar surface is uneven with many pores and poor 


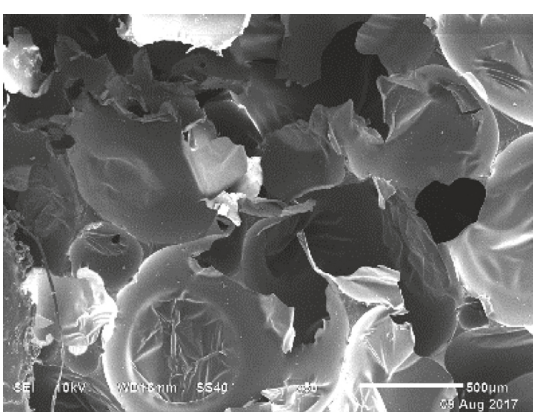

(a)

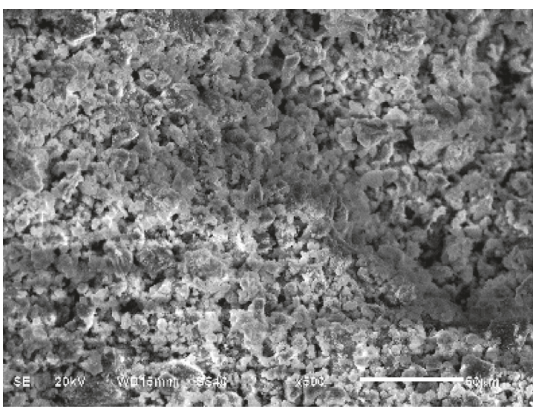

(c)

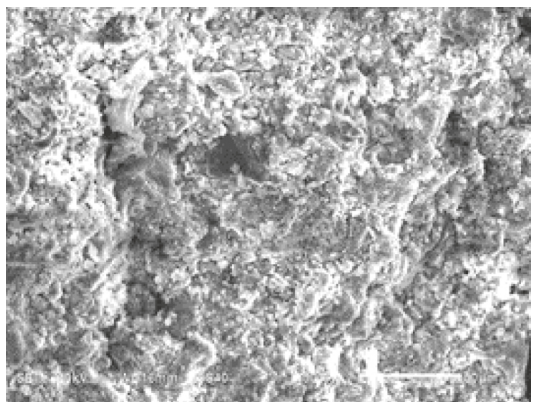

(e)

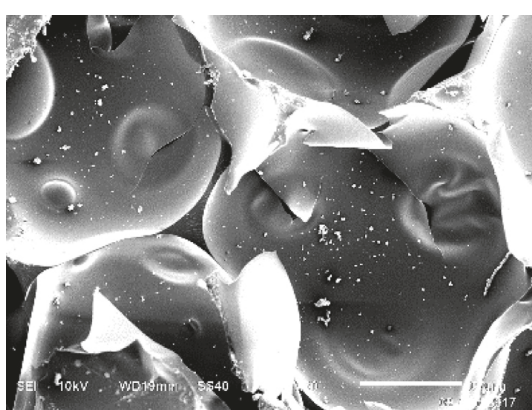

(b)

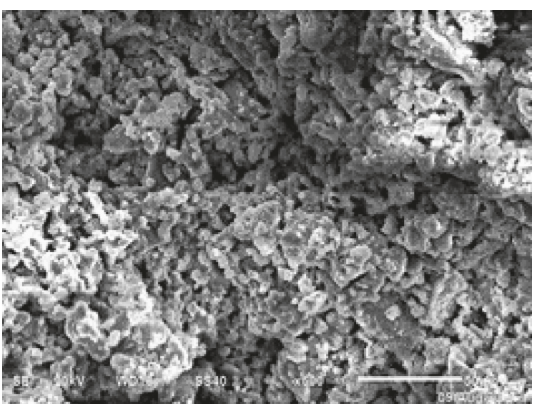

(d)

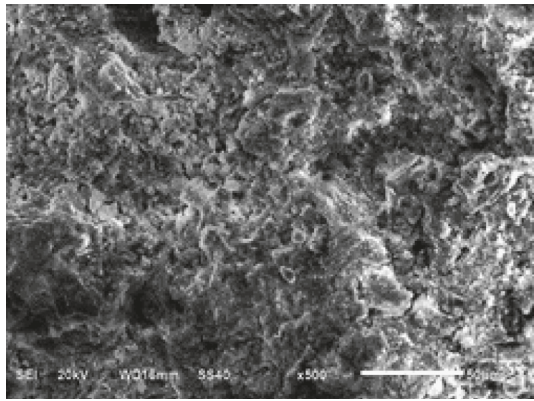

(f)

Figure 8: Microstructure comparison of three kinds of materials. (a) First day (×50). (b) Seventh day (×50). (c) First day ( $\times 500)$. (d) Seventh day $(\times 500)$. (e) First day $(\times 500)$. (f) Seventh day $(\times 500)$.

compactness after 7 days curing. The surface of the new material after 7 days curing is more compact with better borehole sealing effect than that of the new material after 1day curing (Figure $8(\mathrm{f})$ ).

\section{Conclusion}

To solve the problems on borehole sealing and microfissure sealing through application of material composite technology, research is conducted for the development of laboratory materials, performance test, and comparisons with traditional borehole sealing material. The following conclusions are obtained:

(1) Cement types exert a significant effect on the sealing performance of cement-based borehole sealing materials. Therefore, cement should be selected carefully before determining the cement-based borehole sealing materials.
(2) $52.5 \mathrm{R}$ sulfoaluminate cement is selected as the major ingredient and the fiber expansive agent as minor ingredient to produce a new kind of borehole sealing material. Performance tests' results demonstrate that when the water-cement ratio is 0.4 and the amount of fiber expansive agent is $10 \%$, the optimum expansion performance and compressive strength are obtained. The compressive strength after 1 day reaches $16 \mathrm{MPa}$, thereby satisfying the compressive strength requirement of borehole sealing material under $30 \mathrm{MPa}$ water infusion pressure.

(3) The microstructures of the new and traditional materials are observed and analyzed with a scanning electron microscope. Amplified images show that the surface of the new material is compact without interconnecting holes. Moreover, polyurethane forms honeycomb-like reticular formation and cavity array; the large pore space of cement mortar results in poor compactness. The expansion performance, 
compressive strength, and compactness of new borehole sealing material are all superior to those of traditional borehole sealing materials. The new material provides a new approach for underground coal seam infusion.

\section{Conflicts of Interest}

The authors declare that there are no conflicts of interest.

\section{Acknowledgments}

This work was supported by the National Key Research and Development Program of China (Project no. 2017YFC0805201), the National Natural Science Foundation of China (Project nos. 51574158 and 51674158), the Taishan Scholar Talent Team Support Plan for Advantaged \& Unique Discipline Areas, the Source Innovation Program (Applied Research Special-Youth Special) of Qingdao (Project No. 171-1-38-jch), and the Shandong University of Science and Technology Research Fund (Project no. 2015JQJH105).

\section{References}

[1] W. Yang, B. Q. Lin, and J. T. Xu, "Gas outburst affected by original rock stress direction," Natural Hazards, vol. 72, no. 2, pp. 1063-1074, 2014.

[2] L. Yan-qiang, Q. Yue-ping, Y. Xiao-bin, and T. Liang, "New progress on coal mine dust in recent ten years," Procedia Engineering, vol. 26, pp. 738-743, 2011.

[3] Y. Ji, T. Ren, P. Wynne, Z. Wan, Z. Ma, and Z. Wang, "A comparative study of dust control practices in Chinese and Australian longwall coal mines," International Journal of Mining Science and Technology, vol. 26, no. 2, pp. 199-208, 2016.

[4] X. H. Zhou, K. Xu, Q. J. Qi, and X. Wu, "Fuzzy clustering analysis and application of the degree of difficulty of coal seam water injection," Advanced Materials Research, vol. 962, pp. 939-945, 2014.

[5] W. M. Cheng, W. Nie, G. Zhou, Y. Yu, Y. Ma, and J. Xue, "Research and practice on fluctuation water injection technology at low permeability coal seam," Safety science, vol. 50, no. 4, pp. 851-856, 2012.

[6] C. Zhai, X. Xiang, Q. Zou, X. Yu, and Y. Xu, "Influence factors analysis of a flexible gel sealing material for coal-bed methane drainage boreholes," Environmental Earth Sciences, vol. 75, no. 5, p. 385, 2016.

[7] X. Xiang, C. Zhai, Y. Xu, X. Yu, and J. Xu, "A flexible gel sealing material and a novel active sealing method for coalbed methane drainage boreholes," Journal of Natural Gas Science and Engineering, vol. 26, pp. 1187-1199, 2015.

[8] H. Wang, Q. Wang, F. Min, and J. Chen, "Research progress of grouting sealing materials," Materials Review, vol. 13, p. 25, 2013.

[9] P. Termkhajornkit, T. Nawa, M. Nakai, and T. Saito, "Effect of fly ash on autogenous shrinkage," Cement and Concrete Research, vol. 35, no. 3, pp. 473-482, 2005.

[10] C. D. Atiş, "High-volume fly ash concrete with high strength and low drying shrinkage," Journal of materials in civil engineering, vol. 15, no. 2, pp. 153-156, 2003.

[11] P. Nath and P. Sarker, "Effect of fly ash on the durability properties of high strength concrete," Procedia Engineering, vol. 14, pp. 1149-1156, 2011.
[12] P. Chindaprasirt, S. Homwuttiwong, and V. Sirivivatnanon, "Influence of fly ash fineness on strength, drying shrinkage and sulfate resistance of blended cement mortar," Cement and Concrete Research, vol. 34, no. 7, pp. 1087-1092, 2004.

[13] S. K. Lim, C. S. Tan, K. P. Chen, M. L. Lee, and W. P. Lee, "Effect of different sand grading on strength properties of cement grout," Construction and Building Materials, vol. 38, pp. 348-355, 2013.

[14] G. Ni, B. Lin, C. Zhai, Q. G. Li, X. Z. Li, and C. S. Zheng, "Microscopic properties of drilling sealing materials and their influence on the sealing performance of boreholes," Journal of University of Science and Technology Beijing, vol. 35, no. 5, pp. 572-579, 2013.

[15] Z. L. Ge, X. D. Mei, Y. Y. Lu, B. W. Xia, and J. F. Chen, "Mechanical model and test study of sealed drilling for hydraulic fracturing in underground coal mines," Rock and Soil Mechanics, vol. 35, no. 7, pp. 1907-1920, 2014.

[16] C. Zhai, X. Xiang, X. Yu, S. Peng, G. H. Ni, and M. Li, “Sealing performance of flexible gel sealing material of gas drainage borehole," Journal of China University of Mining and Technology, vol. 42, no. 6, p. 1004, 2013.

[17] C. Zhai, Z. Hao, and B. Q. Lin, "Research on a new composite sealing material of gas drainage borehole and its sealing performance," Procedia Engineering, vol. 26, pp. 1406-1416, 2011.

[18] Z. Cheng, Y. Xu, N. Guanhua, L. Min, and H. Zhiyong, "Microscopic properties and sealing performance of new gas drainage drilling sealing material," International Journal of Mining Science and Technology, vol. 23, no. 4, pp. 475-480, 2013.

[19] Q. Liu, Y. Cheng, L. Yuan, Y. Fang, D. Shi, and S. Kong, “A new effective method and new materials for high sealing performance of cross-measure CMM drainage boreholes," Journal of Natural Gas Science and Engineering, vol. 21, pp. 805-813, 2014.

[20] Z. Ge, X. Mei, Y. Lu, J. Tang, and B. Xia, “Optimization and application of sealing material and sealing length for hydraulic fracturing borehole in underground coal mines," Arabian Journal of Geosciences, vol. 8, no. 6, pp. 3477-3490, 2015. 


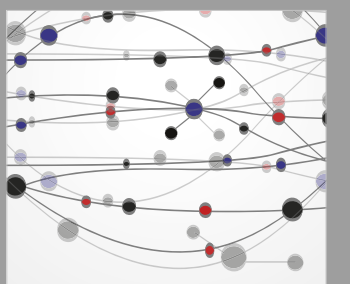

The Scientific World Journal
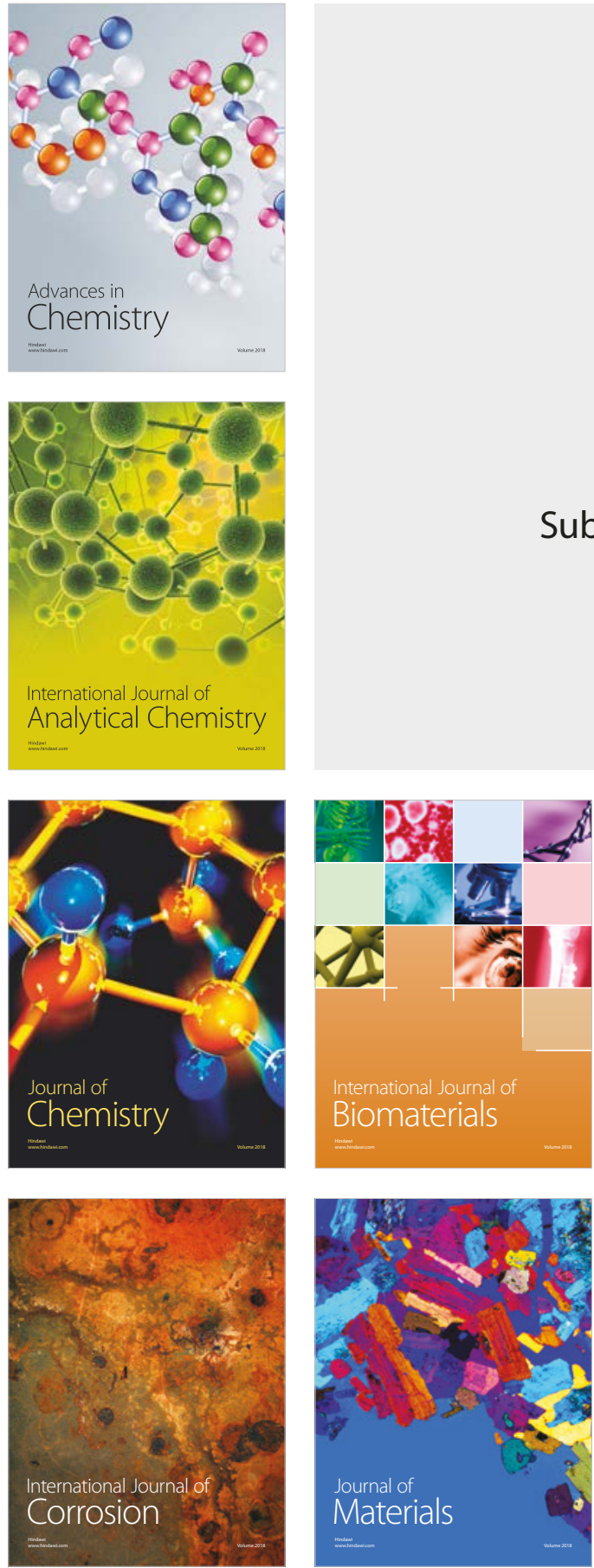

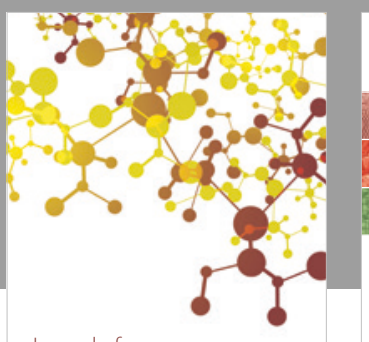

Journal of

Applied Chemistry
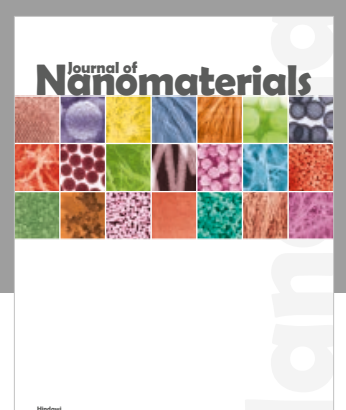

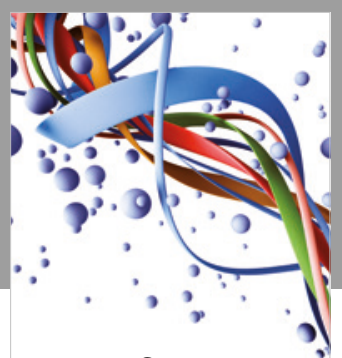

Scientifica

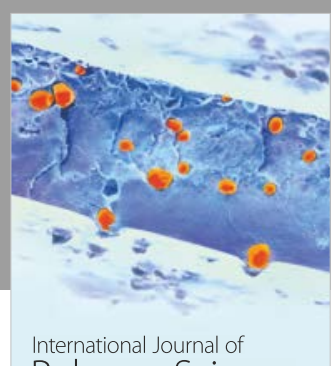

Polymer Science

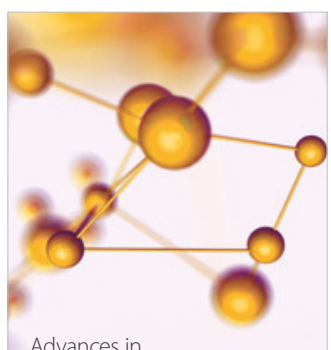

Physical Chemistry
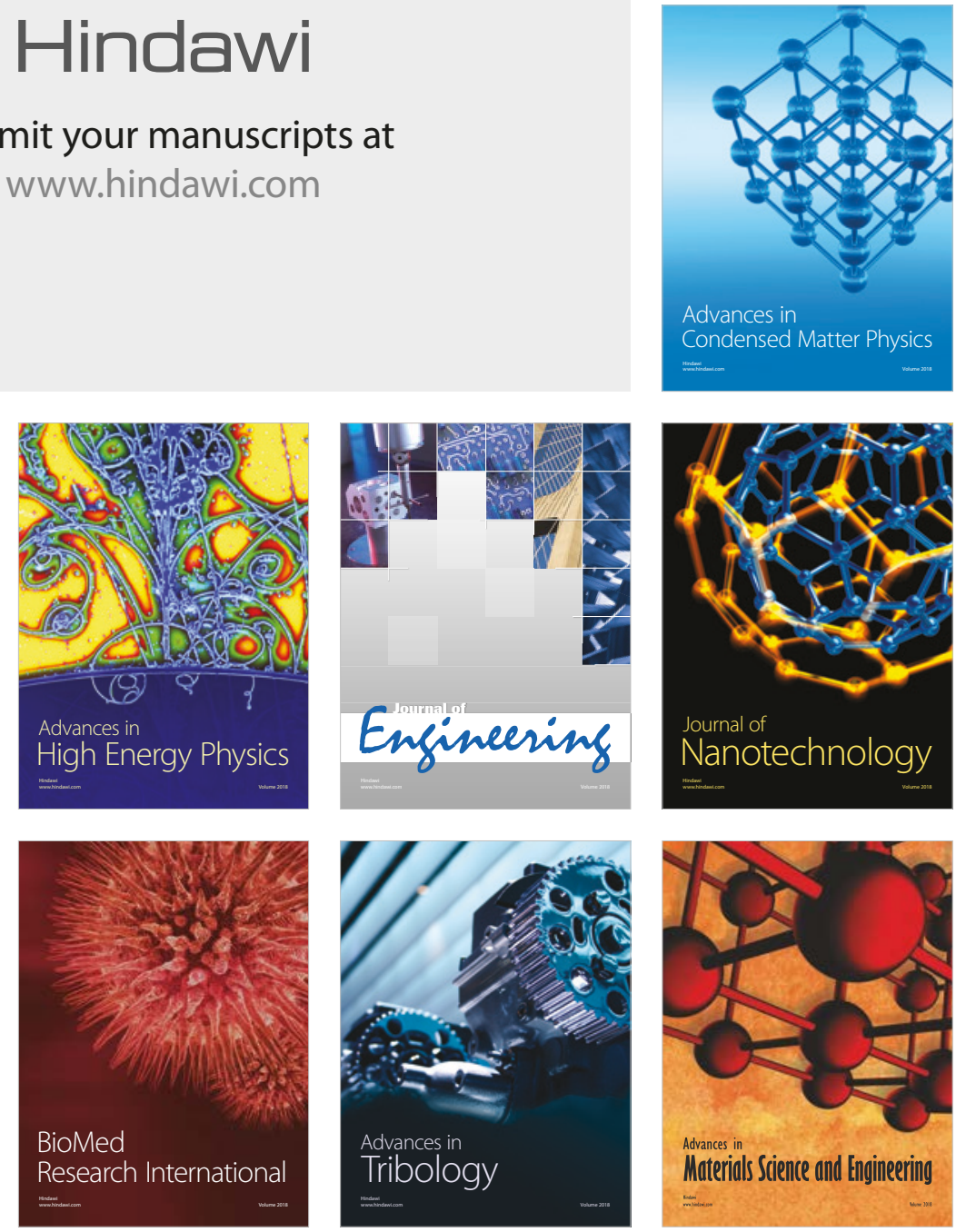